\title{
Doctorate gets a lesson in management
}

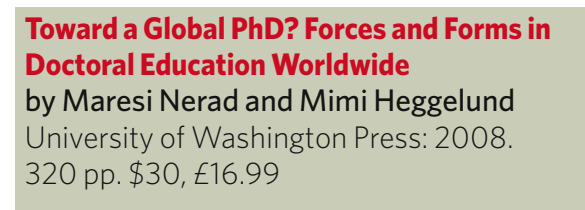

Higher education is increasingly market driven, but its most expensive product - the doctorate - is more popular than ever. Doctoral student numbers continue to rise as funding bodies support them with new initiatives.

Doctorates are expensive. For sponsors, spending around US $\$ 200,000$ on a single individual can produce anxiety. For graduate students, the direct expenses are compounded by the cost of three or more years out of the labour market.

Given this investment, expectations of doctorates are increasing. This pressure is a thread through Toward a Global PhD, the product of a 2005 seminar convened in Seattle by the Center for Innovation and Research in Graduate Education at the University of Washington. The centre's director, Maresi Nerad, and Mimi Heggelund, its international coordinator, bring together 13 comprehensive reviews of doctoral education in 14 countries.

Nerad and Heggelund see doctoral education as the "primary source of research productivity and innovation in the global knowledge economy". They argue that it must both supply researchers and leaders in a wide range of occupations. Postgraduate training needs to instil skills alongside knowledge. European employers, for example, complain that doctoral graduates are too specialized and communicate poorly. To generate those who can "participate effectively in a corporate environment", collaboration must be promoted. International values must also be respected. Developing countries hope that the acquisition of such talents is not accompanied by a brain drain.

These varied needs must be addressed without compromising core skills or quality. A grounding in research methods remains key, along with knowledge of emerging areas such as ethics and intellectual property. International standards must be consistent and recognizable, despite vastly different resources. Candidates must also complete their studies and submit theses within a reasonable time.

Implementing these goals is difficult. The book's editors recognize that they only define parameters for future work, but make a noble attempt to draw conclusions by bringing together material that is not widely available. Each review is thorough and contains

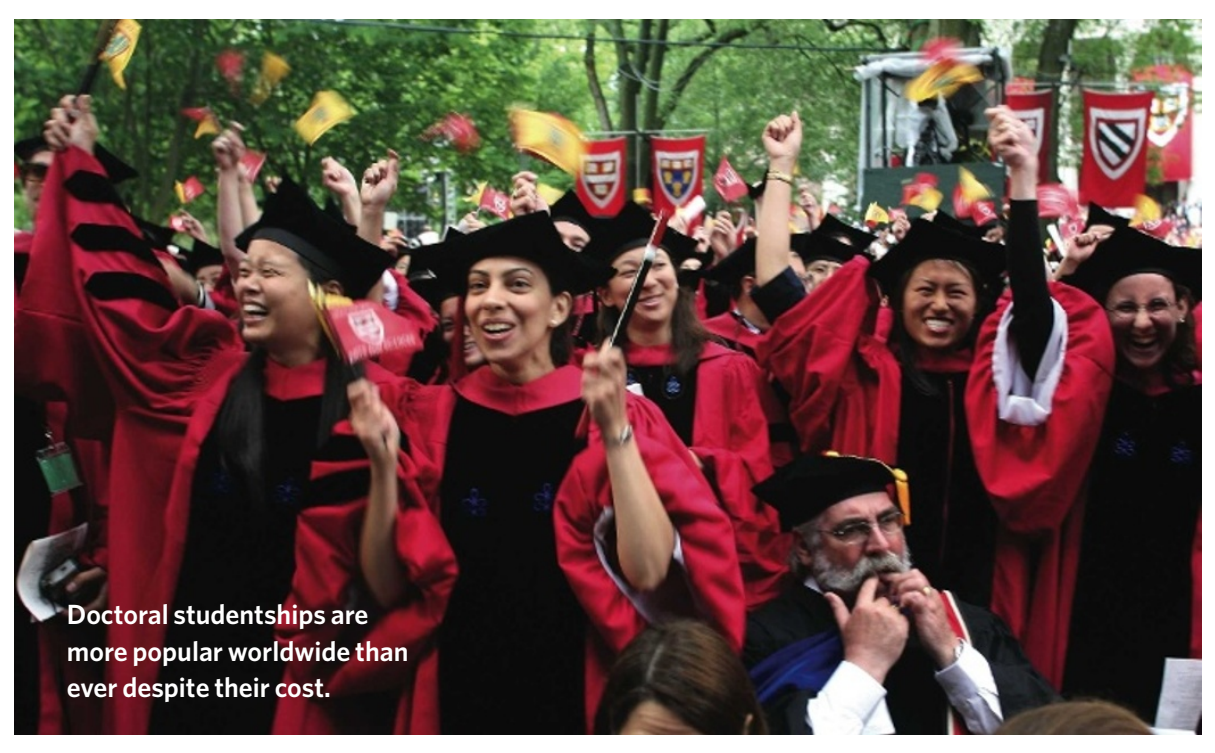

sufficient background on policy, and most analyse probable future developments. A key theme is the inequality of resources, numbers and research agendas. Other themes include the 'mode 2' team-based educational model developed by Michael Gibbons and others, brain drain, and the Bologna proposals for unifying doctoral education practices in the European Union.

The editors identify 15 future education trends, which reflect these and other themes including commoditization, the market economy, and the increasing use of English. Doctoral education, despite its growth, is now subject to more planning and direction than ever. The growth of formal evaluation mechanisms, supervision panels, explicitly stated admission standards and data collection are all examples. Yet such planning does not necessarily imply a narrowing focus. Doctorates are also becoming more international and more interdisciplinary, and some countries explicitly demand more diverse candidates.

Some chapters are too descriptive and view the problem disproportionately from the supply side, or are too conservative in identifying potential developments. In discussing globalization and brain drain, for example, the authors identify a trend for doctoral students to spend time out of their home country. More evidence of what works well would have been useful. Many sponsors and institutions have experimented with split-site doctorates, and it would be interesting to know how these vary in popularity, cost, completion rates and prestige.

Doctorates obtained by distance learning are also slowly increasing, yet this merits only one entry in the book's index. Further discussion of this would have been helpful, such as asking if distance learning provides a model for increasing supply while reducing unit cost, or if such opportunities improve equity by making high-quality supervision accessible to those unable to leave their jobs and countries. Other questions include whether distance learning helps to address brain drain issues, or if remote learners can form close bonds with supervisors.

The authors should also have scrutinized the economics of the $\mathrm{PhD}$ in more detail. They note that doctorates now seem to be aimed at solving specific challenges in developing industries rather than being pursued out of curiosity, for exploration or for love of a specific field. This has implications. Future education planners will need to become more familiar with their market - its needs, limitations and vulnerabilities. Experience suggests that, although demand for international education is increasing, the patterns of growth are uneven and complex. Given that 17 of the world's top universities are in the United States, this unevenness will be with us for some time to come.

In the best tradition of doctoral candidates, Maresi and Heggelund recognize the need for more research. Criticisms aside, Toward a Global $P h D$ provides a useful framework for planners and providers alike.

John Kirkland is Deputy Secretary-General

(Development) at the Association of

Commonwealth Universities, 20-24 Tavistock

Square, London WC1H 9HF, UK.

e-mail: j.kirkland@acu.ac.uk 